\title{
Foods with added fiber improve stool frequency in individuals with chronic kidney disease with no impact on appetite or overall quality of life
}

\author{
Younis A Salmean ${ }^{1}$, Gordon A Zello² and Wendy J Dahl ${ }^{\text {** }}$
}

\begin{abstract}
Background: Fiber intake may be low in individuals with chronic kidney disease (CKD) due to diet restriction and/or poor appetite associated with uremic symptoms, contributing to constipation and reduced quality of life. This report describes the effects of foods with added fiber on gastrointestinal function and symptoms, clinical markers, and quality of life in CKD patients.
\end{abstract}

Findings: Adults with CKD ( $n=15 ; 9$ F, 6 M; $66 \pm 15 \mathrm{y})$ were provided with cereal, cookies and snack bars without added fiber for 2 weeks, followed by similar foods providing $23 \mathrm{~g} / \mathrm{d}$ of added fiber for 4 weeks, to incorporate into their usual diets. Participants completed the Kidney Disease Quality of Life (KDQOL-36) questionnaire, the Simplified Nutritional Appetite Questionnaire (SNAQ) and the Epworth Sleepiness Scale (ESS) bi-weekly, the Gastrointestinal Symptom Rating Scale (GSRS) weekly, and daily stool frequency and compliance. Control and intervention serum cholesterol and glucose were assessed. Providing $23 \mathrm{~g} / \mathrm{d}$ of added fiber increased stool frequency $(1.3 \pm 0.2$ to $1.6 \pm$ 0.2 stools $/ \mathrm{d} ; \mathrm{P}=0.02)$, decreased total cholesterol $(175 \pm 12$ to $167 \pm 11 \mathrm{mg} / \mathrm{dL} ; \mathrm{P}=0.02)$ and improved TC:HDL ratio ( $4.0 \pm 0.3$ to $3.7 \pm 0.2 ; P=0.02$ ). GSRS and SNAQ scores did not change, but SNAQ scores suggested poor appetite in 7 participants with or without added fiber. KDQOL Mental Health Composite decreased from $53 \pm 2$ to $48 \pm 2$ $(P=0.01)$ while Physical Health Composite increased from $31 \pm 2$ to $35 \pm 3(P=0.02)$, with no change in overall QOL. The ESS score decreased from $10 \pm 1$ to $8 \pm 1(P=0.04)$.

Conclusion: Consuming foods with added fiber may be an effective means of increasing fiber intakes, improving stool frequency, and lipid profile in individuals with CKD.

Trial registration: ClinicalTrials.gov, \# NCT01842087

Keywords: Chronic kidney disease, Fiber, Quality of life, Gastrointestinal function, Appetite, GSRS, SNAQ, ESS

\section{Introduction}

The fiber intake of Americans falls dramatically short of the amount recommended for good health, with the majority of adults and children averaging half of the recommendation [1]. The consumption of fiber has been decreasing over the past decade and is lower in AfricanAmerican adults, a population at increased risk of developing CKD [2] and kidney failure [3]. Patients with advanced CKD may need to limit foods naturally rich in fiber such as whole grains, legumes and certain fruits

\footnotetext{
*Correspondence: wdahl@ufl.edu

${ }^{1}$ Food Science and Human Nutrition, University of Florida, 359 FSHN Building Newell Drive, Gainesville, FL 32611, USA

Full list of author information is available at the end of the article
}

and vegetables due to their phosphorous and/or potassium contents [4]. Poor appetite, commonly experienced by individuals with uremia due to CKD, may also negatively impact fiber intake. Thus, individuals with CKD may have fiber intakes lower than that of the healthy population.

Dietary fiber has been shown to confer several health benefits related to cardiovascular disease and diabetes. Isolated fibers, specifically viscous fibers, are known to attenuate blood glucose response and to lower LDL and total cholesterol [5]. Whole foods, such as pulses, that are high in dietary fiber also have been shown to demonstrate reductions in glycemia [6] and to improve cholesterol profile $[7,8]$. Diabetes and hypertension are the two 
leading causes of renal failure accounting for about $60 \%$ of all new cases [3], while cardiovascular disease is the most likely cause of death [9]. Given that many with CKD have diabetes and all are at risk for cardiovascular disease, low fiber intake may be particularly detrimental in this population.

Individuals with CKD experience a significant decline in quality of life with disease progression [10]. This may be attributed mainly to uremia, which includes symptoms such as anorexia, constipation, nausea, fatigue and decreased mental acuity [11]. Increases in the number and severity of symptoms lead to a more pronounced decline in quality of life. These uremic symptoms are assumed to be mainly the result of accumulation of organic molecules that are normally cleared by the kidneys [11]. Studies have shown that supplementing fiber leads to decreased uremic molecules [12-14]; hence fiber may positively impact quality of life by reducing uremia, constipation in particular. However, certain fibers, such as oligofructose, may reduce energy intake, possibly through reduced appetite [15]. As individuals with CKD are at risk for malnutrition, decreased appetite may be a potential risk with added fiber.

Foods with added fiber may be of benefit to individuals with CKD. We hypothesized that incorporating commercially-available foods with added fiber into the diets of individuals with CKD would lead to improved gastrointestinal function and quality of life, without impacting clinical markers and symptoms. This study was conducted according to the guidelines laid down in the Declaration of Helsinki and all procedures involving human subjects were approved by the University of Florida's Institutional Review Board 1 (IRB\#16-2010). Written informed consent was obtained from all subjects. This study is registered with ClinicalTrials.gov, registration \# NCT01842087.

\section{Findings}

A six-week, single-blind, rolling admission study was carried out. As reported previously, nephrology patient charts $(n=270)$ were screened for eligible participants using the inclusion criteria: > $18 \mathrm{y}$, eGFR of $\leq 50 \mathrm{~mL} / \mathrm{min} / 1.73 \mathrm{~m}^{2}$ (stage 3, 4 and 5 but not on dialysis), no acute kidney injury or glomerulonephritis, and no immunosuppressant medications [16]. Participants with CKD were provided with control foods (cookies, snack bars and breakfast cereal) containing $<2 \mathrm{~g} /$ day of fiber for 2 weeks, followed by similar foods providing $23 \mathrm{~g} /$ day (pea hull, inulin and resistant corn dextrin) for 4 weeks, to incorporate into their usual diets. Four weeks was chosen for the length of the fiber intervention to allow for potential changes in gut microbiota, and its predicted impacts on previously reported outcomes [16], whereas the control was limited to 2 weeks to minimize participant burden. Participants completed the
Kidney Disease Quality of Life (KDQOL-36) questionnaire [17], the Simplified Nutritional Appetite Questionnaire (SNAQ) [18] and the Epworth Sleepiness Scale [19] biweekly at clinic visits, and the Gastrointestinal Symptom Rating Scale (GSRS) [20], weekly. A SNAQ score of $\leq 14$ indicates poor appetite and significant risk of at least 5\% weight loss within six months. The Epworth Sleepiness Scale was used to assess participants likelihood of daytime sleepiness. Scores ranging from 10 to 12 indicate a boarderline risk of daytime sleep propensity, while a range of 12 to 24 indicates an abnormal tendency. In addition, participants recorded daily stool frequency and compliance. Fasting serum glucose and cholesterol were assessed by clinically standardized methods on blood samples collected on days 1 and 14 of the control period and days 28 and 42 of the intervention period. Paired $t$-test was used for comparisons of parameters and scores for each test between periods. Significance was considered to be $\mathrm{p}<0.05$. All data are presented as mean $\pm \mathrm{SE}$.

Seventeen individuals with stage 3 to 5 CKD $(66 \pm 15$ y) consented to participate in the study. Sixteen enrolled and 15 completed the study. Of those completing the study, four patients were in stage 3,10 were in stage 4, and one was in stage 5 (pre-dialysis). Eleven participants were White and 4 were African American, with 9 females and 6 males. With a daily intake of $16.8 \mathrm{~g}$ of fiber [16] of the $23 \mathrm{~g} / \mathrm{d}$ offered, daily stool frequency increased with the fiber intervention from $1.3 \pm 0.2$ to $1.6 \pm$ 0.2 stools per day $(P=0.02)$. There were no changes in fasting blood glucose (Table 1). Total cholesterol (TC) decreased from $175 \pm 12$ to $167 \pm 11 \mathrm{mg} / \mathrm{dL}(\mathrm{P}=0.02)$ and a strong trend was found for decreased LDL cholesterol $(100 \pm 8$ to $93 \pm 7 \mathrm{mg} / \mathrm{dL} ; \mathrm{P}=0.05)$. TC:HDL ratio declined from $4.0 \pm 0.3$ during control to $3.7 \pm 0.2$ during the fiber intervention ( $\mathrm{P}=0.02)$ (Table 1). No significant changes were found in the average SNAQ scores with the fiber intervention (Table 1). Epworth Sleepiness Scale score decreased from $10 \pm 1$ at control to $8 \pm 1$ with the fiber intervention $(\mathrm{P}=0.04)$ (Table 1$)$. The GSRS scores indicated low gastrointestinal distress and did not change from control $(23 \pm 1)$ to fiber intervention $(22 \pm 1)$. There were no changes in the KDQOL-36 $6^{\text {mx }}$ overall mean score or with the Symptom/Problem List, Effects of Kidney Disease and Burden of Kidney Disease subscales throughout the study (Table 1). However, the Physical Component Summary subscale mean score increased from $31 \pm 2$ during control to $35 \pm 3$ during fiber intervention $(\mathrm{p}=0.02)$. The mean score for the Mental Component Summary subscale was significantly lower during intervention $(48 \pm 2)$ compared to control (53 \pm 2$)$ $(P=0.01)$. Comparisons between males and females showed no significant differences (data not reported).

Constipation is a common symptom of uremia contributing to decreased quality of life in individuals with 
Table 1 Clinical markers, symptoms and quality of life

\begin{tabular}{|c|c|c|c|}
\hline & Control period (no fiber added) & Intervention period with added fiber & $P$ value \\
\hline Weight (kg) & $89 \pm 6$ & $90 \pm 6$ & NS \\
\hline \multicolumn{4}{|l|}{ Clinical markers } \\
\hline Glucose mg/dL & $136 \pm 29$ & $146 \pm 25$ & NS \\
\hline $\mathrm{LDL} \mathrm{mg} / \mathrm{dL}$ & $100 \pm 8$ & $93 \pm 7$ & $P=0.05$ \\
\hline $\mathrm{HDL} \mathrm{mg/dL}$ & $47 \pm 4$ & $47 \pm 4$ & NS \\
\hline Total CHOL mg/dL & $175 \pm 12$ & $167 \pm 11$ & $P=0.02$ \\
\hline $\mathrm{TG} \mathrm{mg} / \mathrm{dL}$ & $165 \pm 21$ & $154 \pm 21$ & NS \\
\hline CHOL:HDL ratio & $4.0 \pm 0.3$ & $3.7 \pm 0.2$ & $P=0.02$ \\
\hline \multicolumn{4}{|l|}{ KDQOL-36 $6^{\mathrm{TM}}$} \\
\hline Symptom/Problem list & $78 \pm 3$ & $80 \pm 3$ & NS \\
\hline Effects of kidney disease & $84 \pm 4$ & $87 \pm 3$ & NS \\
\hline Burden of kidney disease & $67 \pm 6$ & $73 \pm 6$ & NS \\
\hline Physical component summary & $31 \pm 2$ & $35 \pm 3$ & $P=0.02$ \\
\hline Mental component summary & $53 \pm 2$ & $48 \pm 2$ & $P=0.01$ \\
\hline Overall mean scores & $63 \pm 3$ & $64 \pm 3$ & NS \\
\hline \multicolumn{4}{|l|}{ Symptoms } \\
\hline SNAQ & $14 \pm 1$ & $14 \pm 1$ & NS \\
\hline GSRS & $23 \pm 1$ & $22 \pm 1$ & NS \\
\hline ESS & $10 \pm 1$ & $8 \pm 1$ & $P=0.04$ \\
\hline Stool frequency & $1.3 \pm 0.2$ & $1.6 \pm 0.2$ & $P=0.02$ \\
\hline
\end{tabular}

advanced CKD. Foods with added fiber may provide a remedy. With the provision of $23 \mathrm{~g} / \mathrm{d}$ of added fiber, participants in the current study improved their fiber intakes, consuming an additional $16.8 \mathrm{~g}$, on average, of added fiber, in addition to the $9.7 \mathrm{~g}$ fiber in their background diet [16]. The majority of participants achieved their Adequate Intake for fiber [16]. Stool frequency increased, due in part to the $4 \mathrm{~g} / \mathrm{d}$ of insoluble pea hull fiber provided in the foods with added fiber. This finding is in agreement with a previous study where $4 \mathrm{~g} / \mathrm{d}$ of pea hull fiber improved stool frequency in elderly residing in a long term care home [21]. The inulin may have also contributed to increased stool frequency as this effect has been demonstrated in constipated elderly [22].

A concern with providing the foods with added fiber was the additional available carbohydrate provided. However, no change in body weight or energy intake occurred over the six-week study [16]. Lipid profile improved with the fiber intervention, although no viscous fiber was provided and thus, the change may be due to the participants' reduced intake of fat, as reported previously [16]. Given the significant cardiovascular risk of the CKD patient population, the improvements in $\mathrm{TC}$ and LDL, although unexpected, were positive findings.
The fiber intervention had little impact on symptom scores with the exception of sleepiness. The change in ESS score suggests a drop from borderline risk of daytime sleepiness to normal. Participants reported an average SNAQ score of 14 during control with seven participants at risk for future weight loss due to poor appetite. During control, there were five participants with average scores of 10 or higher compared to only three participants during intervention period. As malnutrition is of concern in the later stages of CKD [23], the impact of added fiber on appetite justifies further investigation.

CKD patients, with creatinine clearance of $<60 \mathrm{~mL} /$ $\min / 1.73 \mathrm{~m}^{2}$, report lower physical function independent of age, sex, and other confounding factors [24]. In dialysis patients, both the Physical and Mental Components of the KDQOL-36 were consistent predictors of hospitalizations and mortality rates with each point increase in either component reducing mortality relative risk by $2 \%$, and hospitalization relative risk by $2 \%$ and $1 \%$, respectively [25]. Thus, the 4-point improvement in the Physical Component Summary and the decrease in Mental Component Summary reported in this study may be of clinical significance. The improved physical and functional health may be explained by the increased stool 
frequency as it has been reported that quality of life is significantly impacted by constipation [26]. The increase in the Physical Component Summary also may be due to the improved kidney function reported previously [16]. The Mental Component Summary was lower during the intervention period when compared to control. This decline in mean score may be explained by those participants who did not respond to the intervention as five out of seven participants who reported lower scores during intervention were non-responders. It has also been suggested that changes in Mental Component Summary are unlikely to be correlated to kidney function among those in stage 4 and 5 of the disease [10], but may be associated with variables that were not explored.

This study had limitations. The sample of CKD patients was diverse, including both White and AfricanAmericans in CKD stages 3, 4 and 5, therefore too small to allow for statistical comparisons among race and stage of disease. The results of this study are considered pilot data and thus, further research is needed to confirm the findings presented.

Fiber intakes of the general population fall far below the recommendation and those with CKD may be at increased risk from this shortfall. Foods with added fiber, specifically those that are conducive to the restrictions of a renal diet, may provide health benefits to those with CKD, particularly improved regularity, lipid profile and the physical/functional aspects of quality of life.

\section{Abbreviations \\ CKD: Chronic kidney disease; LDL: Low density lipoprotein; TC: Total cholesterol.}

\section{Competing interests}

The study was funded by the Saskatchewan Pulse Growers, Saskatoon, Canada. The authors have no other competing interests.

\section{Authors' contributions}

YAS refined the study design, carried out the study, collected the data, performed the statistical analysis and assisted with drafting the manuscript. WJD and GAZ initiated the study by proposing the original study and securing funding for the work. WJD was responsible for the coordination of the study and drafting the manuscript. GAZ assisted with drafting the manuscript. All authors read and approved the final manuscript.

\section{Acknowledgements}

We would like to thank James Colee and Muna Canales for directional support, Mark Segal for providing direction and patient referral support and the participants for completing the study.

\section{Author details}

${ }^{1}$ Food Science and Human Nutrition, University of Florida, 359 FSHN Building Newell Drive, Gainesville, FL 32611, USA. 'College of Pharmacy and Nutrition, University of Saskatchewan, 110 Science Place, Saskatoon SK S7N 5C9, Canada.

Received: 18 March 2013 Accepted: 29 November 2013 Published: 5 December 2013

\section{References}

1. USDA: In What We Eat in America National Health and Nutritional Examination Survey (NHANES) 2005-2006. Edited by Beltsville MD.
Washington, DC: Food Surveys Research Group Beltsville Human Nutrition Research Center, Agricultural Research Service, USDA; 2003.

2. Stevens J, Ahn K, Juhaeri, Houston D, Steffan L, Couper D: Dietary fiber intake and glycemic index and incidence of diabetes in AfricanAmerican and white adults: the ARIC study. Diabetes Care 2002, 25:1715-1721.

3. NIH US Renal Data System: USRDS 2012 Annual Data Report: Atlas of Chronic Kidney Disease and End-Stage Renal Disease in the United States. Bethesda, MD: National Institutes of Health, National Institute of Diabetes and Digestive and Kidney Diseases; 2012.

4. Nelms M, Sucher KP, Lacey K, Long Roth S: Nutrition Therapy and Pathophysiology. 2nd edition. Belmont, CA: Thomson Brooks/Cole; 2010.

5. Institute of Medicine: Dietary Reference Intakes for Energy, Carbohydrate, Fiber, Fat, Fatty Acids, Cholesterol, Protein, and Amino Acids (Macronutrients). Washington, D.C: The National Academies Press; 2005.

6. Rizkalla SW, Bellisle F, Slama G: Health benefits of low glycaemic index foods, such as pulses, in diabetic patients and healthy individuals. Br J Nutr 2002, 88:S255-S262.

7. Zhang Z, Lanza E, Kris-Etherton PM, Colburn NH, Bagshaw D, Rovine MJ, Ulbrecht JS, Bobe G, Chapkin RS, Hartman TJ: A high legume low glycemic index diet improves serum lipid profiles in men. Lipids 2010, 45:765-775.

8. Pittaway JK, Robertson IK, Ball MJ: Chickpeas may influence fatty acid and fiber intake in an ad libitum diet, leading to small improvements in serum lipid profile and glycemic control. J Am Diet Assoc 2008, 108:1009-1013.

9. Perazella MA, Khan S: Increased mortality in chronic kidney disease: a call to action. Am J Med Sci 2006, 331:150-153.

10. Gorodetskaya I, Zenios S, McCulloch CE, Bostrom A, Hsu CY, Bindman AB, Go AS, Chertow GM: Health-related quality of life and estimates of utility in chronic kidney disease. Kidney Int 2005, 68:2801-2808.

11. Meyer TW, Hostetter TH: Uremia. N Engl J Med 2007, 357:1316-1325.

12. Younes H, Egret N, Hadj-Abdelkader M, Remesy C, Demigne C, Gueret C, Deteix $P$, Alphonse JC: Fermentable carbohydrate supplementation alters nitrogen excretion in chronic renal failure. J Ren Nutr 2006, 16:67-74.

13. Bliss DZ, Stein TP, Schleifer CR, Settle RG: Supplementation with gum arabic fiber increases fecal nitrogen excretion and lowers serum urea nitrogen concentration in chronic renal failure patients consuming a low-protein diet. Am J Clin Nutr 1996, 63:392-398.

14. Rampton DS, Cohen SL, Crammond VD, Gibbons J, Lilburn MF, Rabet JY, Vince AJ, Wager JD, Wrong OM: Treatment of chronic renal failure with dietary fiber. Clin Nephrol 1984, 21:159-163.

15. Verhoef SP, Meyer D, Westerterp KR: Effects of oligofructose on appetite profile, glucagon-like peptide 1 and peptide YY3-36 concentrations and energy intake. Br J Nutr 2011, 106:1757-1762.

16. Salmean YA, Segal MS, Langkamp-Henken B, Canales MT, Zello GA, Dahl WJ: Foods with added fiber lower serum creatinine levels in patients with chronic kidney disease. J Ren Nutr 2013, 23:e29-e32.

17. Hays RD, Kallich JD, Mapes DK, Coons SJ, Carter WB: Development of the Kidney Disease Quality of Life (KDQOL ${ }^{\mathrm{TM}}$ ) Instrument. Qual Life Res 1994, 3:329-338.

18. Wilson MM, Thomas DR, Rubenstein LZ, Chibnall JT, Anderson S, Baxi A, Diebold MR, Morley JE: Appetite assessment: simple appetite questionnaire predicts weight loss in community-dwelling adults and nursing home residents. Am J Clin Nutr 2005, 82:1074-1081.

19. Johns MW: A new method for measuring daytime sleepiness: the Epworth sleepiness scale. Sleep 1991, 14:540-545.

20. Revicki DA, Wood M, Wiklund I, Crawley J: Reliability and validity of the Gastrointestinal Symptom Rating Scale in patients with gastroesophageal reflux disease. Qual Life Res 1998, 7:75-83.

21. Dahl WJ, Whiting SJ, Healey A, Zello GA, Hildebrandt SL: Increased stool frequency occurs when finely processed pea hull fiber is added to usual foods consumed by elderly residents in long-term care. J Am Diet Assoc 2003, 103:1199-1202.

22. Kleessen B, Sykura B, Zunft HJ, Blaut M: Effects of inulin and lactose on fecal microflora, microbial activity, and bowel habit in elderly constipated persons. Am J Clin Nutr 1997, 65:1397-1402.

23. Carrero JJ, Stenvinkel P, Cuppari L, Ikizler TA, Kalantar-Zadeh K, Kaysen G, Mitch WE, Price SR, Wanner C, Wang AY, ter Wee P, Franch HA: Etiology of the protein-energy wasting syndrome in chronic kidney disease: a consensus statement from the International Society of Renal Nutrition and Metabolism (ISRNM). J Ren Nutr 2013, 23:77-90. 
24. Chow FY, Briganti EM, Kerr PG, Chadban SJ, Zimmet PZ, Atkins RC: Healthrelated quality of life in Australian adults with renal insufficiency: a population-based study. Am J Kidney Dis 2003, 41:596-604.

25. Lowrie EG, Curtin RB, LePain N, Schatell D: Medical outcomes study short form-36: a consistent and powerful predictor of morbidity and mortality in dialysis patients. Am J Kidney Dis 2003, 41:1286-1292.

26. Higgins PD, Johanson JF: Epidemiology of constipation in North America: a systematic review. Am J Gastroenterol 2004, 99:750-759.

doi:10.1186/1756-0500-6-510

Cite this article as: Salmean et al: Foods with added fiber improve stool frequency in individuals with chronic kidney disease with no impact on appetite or overall quality of life. BMC Research Notes 2013 6:510.

\section{Submit your next manuscript to BioMed Central} and take full advantage of:

- Convenient online submission

- Thorough peer review

- No space constraints or color figure charges

- Immediate publication on acceptance

- Inclusion in PubMed, CAS, Scopus and Google Scholar

- Research which is freely available for redistribution 